East African Medical Journal Vol. 86 (Supplement) December 2009

PROGRESS IN BLOOD TRANSFUSION SERVICES IN KENYA FROM THE 1980'S: A REVIEW

M. Oduor, MBChB, MMed (Path),Cert Blood Transfusion Medicine, Director, National Blood Transfusion Services, Kenya, Ministry of Medical Services, P. O. Box 29804 - 00202, Nairobi, Kenya

\title{
PROGRESS IN BLOOD TRANSFUSION SERVICES IN KENYA FROM THE 1980'S: A REVIEW
}

\author{
M. ODUOR
}

\begin{abstract}
Background: Provision of safe and adequate supplies of blood is dependent on a well organised blood transfusion service with dedicated well-trained manpower and resources for the service.

Objective: To provide an overview of the evolution of blood transfusion services in Kenya, from the 1980s to date.

Data sources: Various Government of Kenya publications and websites on blood transfusion related issues. Publications and websites of stakeholders including donors and other partners as well. Personal experience - the author has been in national blood transfusion administration for over five years.

Data selection: Data related to blood transfusion in Kenya on websites and publication were scrutinised.

Data extraction: All selected articles were read.

Data synthesis: All the collected data together with the author's experience were used for this publication.

Conclusion: As part of the effort by the Ministry of Health to reform the health sector, there was need to reorganise departments and divisions within the Ministry. The reorganisation of the blood transfusion service was one such consideration and it was hoped that following this change, there would be better, safer and more efficient provision of blood for transfusion service snation wide. This article documents the evolution of blood transfusion services from the early 1980 s to date.
\end{abstract}

\section{BLOOD TRANSFUSION SERVICES IN KENYA FROM THE 1980S TO DATE}

In the 1980's blood transfusion services in Kenya were hospital-based and were run as part of the hospital laboratory services. Family and replacement donations were the major sources of blood required for transfusion. The larger hospitals struggled to meet their demands and managed their own stock levels while smaller hospitals were incapable of this and often transferred patients requiring transfusions to these larger hospitals. This arrangement of hospital based blood transfusion services (BTS) proved cumbersome to supervise and ensure quality and safety. Additionally, there were logistics problems in the distribution of reagents and other supplies (1).

Being part of the general laboratory, it also became difficult to dedicate staff and equipment to BTS. Running BTS is a costly affair and it was estimated that to provide a unit of safe blood in Africa cost between Kshs. 2,000, (US\$26) to Ksh. 4,000, (US \$ 52). With the advent of human immunodeficiency virus and acquired immunodeficiency syndrome (HIV / AIDS) in the 1980's, people started shying away from donating blood. This led to reduction in the supply of blood resulting in widely apparent shortage of blood for emergencies. This shortage was especially highlighted in 1998 during the famous bomb blast of the United States Embassy in Nairobi.

Progress of blood services in Kenya: The World Health Assembly and the Regional Commonwealth Ministers of Health recommended that their member states develop comprehensive and well coordinated blood transfusion services based on voluntary, non-remunerated blood donation (resolution WHA 28.72 of 1972 and resolution of 1989 respectively) (1). Additionally, the International Society of Blood Transfusion and the International Federation of the Red Cross Society also urged member states to enact effective legislative policies governing operations of blood transfusion and to take any other necessary action to protect and to promote the health of blood donors and recipients $(3,4)$.

In recognition of the above recommendations, and the increasing demand for a safe blood supply and blood transfusion service in the country, the Ministry of Health in consultation with key stakeholders 
developed Kenya'sfirstblood safety policy guidelines for the collection, processing, storage, distribution and supply of blood and blood products in the year 1999
$(5,6)$. These guidelines served as a foundation for the entire programme and guide both policy makers and service providers.

Figure 1

The current organisation of the national blood transfusion

\section{Organogram}

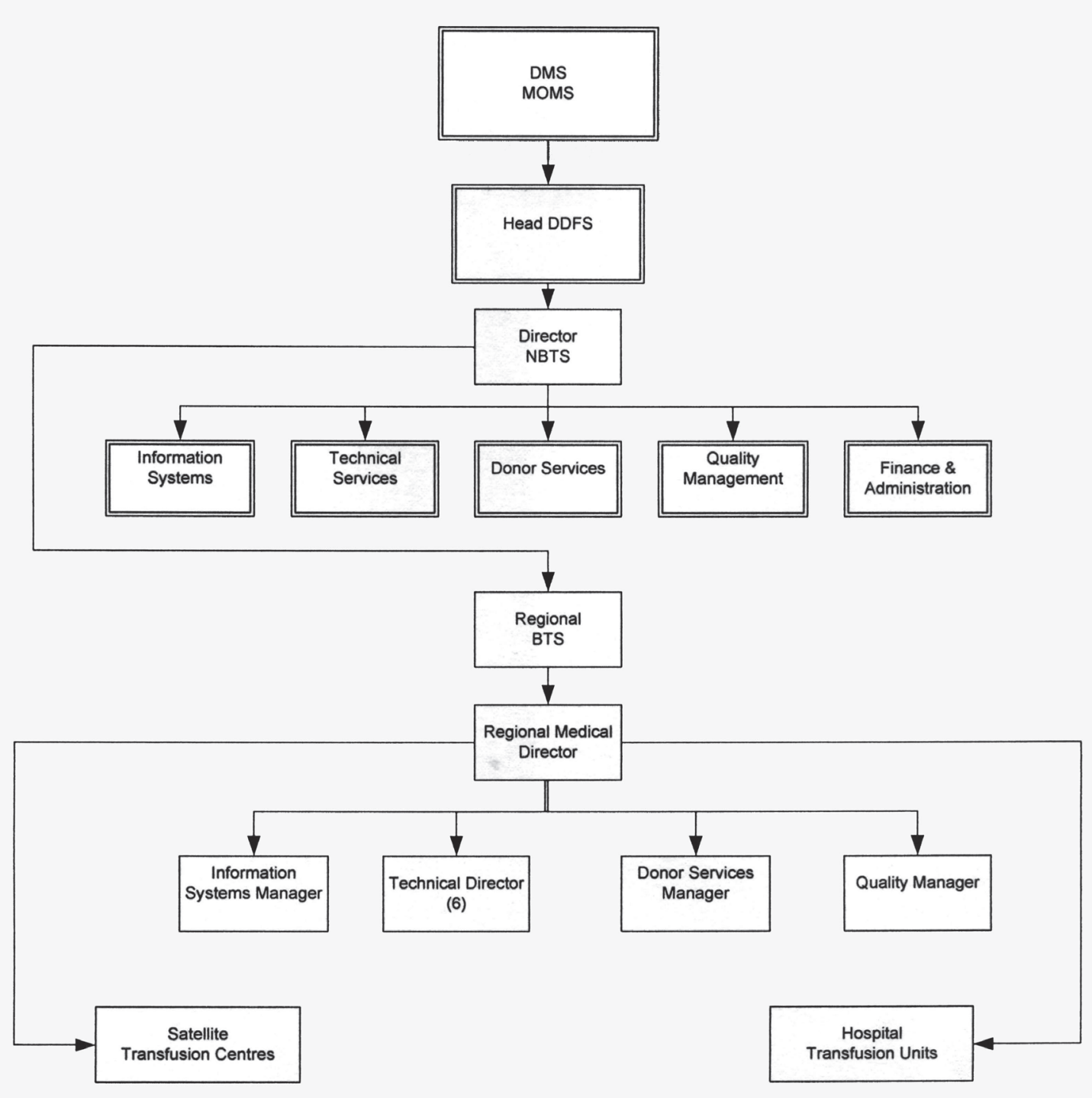

BTS $=$ Blood Transfusion service

DDFS $=$ Department of Diagnostics and Forensic Services DMS $=$ Director of Medical Services NBTS $=$ National Blood Transfusion Services MOMS $=$ Ministry of Medical Services 
With assistance from the United States of America (USA) government through United States Agency for International Development (USAID) and Centre for Disease Control (CDC), Kenya was able to establish national, regional and satellite blood transfusion centres in most parts of the country that responded exclusively to the blood supply needs of their respective regions. These structures were put up between the years 2000 and $2005(6,5)$.

The centres follow the standard operating procedures set forth in the BTS policy guidelines. The new centralised services were more efficient, cost effective, easier to manage and had more stringent quality controls than the previous hospital based system. A National Blood Transfusion Centre was established in Nairobi to provide safe and adequate blood transfusion services in Nairobi region and to oversee all the regional and satellite blood transfusion centres (BTC's) countrywide. Regional centres were established in Kisumu, Mombasa, Nakuru, Embu and Eldoret. These centres centralise the blood transfusion services in their respective areas and more effectively meet the regional needs. Under the direction of the national and regional BTC's satellite centres were operating along the Trans African highway in Voi, Naivasha and Kericho to respond to the increasing number of traffic accidents along the route (1).

The $\mathrm{MoH}$ partnered with the Kenya Red Cross Society to help in mobilising and recruiting a pool of volunteer, non-remunerated blood donors from low risk populations. This was to help reduce the risk of transmitting infectious agents and reduce cost and wastage. Additional satellite centres (Kisii, Machakos and Nyeri) were put up between 2005-2007. Two more satellite centres (Kakamega and Meru) are to be constructed soon. This is to further move blood services nearer to the people $(3,4)$.

The NBTS operated within the department of National Public Health Laboratories until the split of the Ministry of Health into Ministry of Medical Services and Ministry of Public Health and Sanitation in the year 2008 when NBTS started operating within the Department of Diagnostics and Forensic Services (DDFS) in the Ministry of Medical Services (MOMS). It is proposed that NBTS shall eventually evolve to become independent and semiautonomous with its own board of management, its own secretariat and its own funding and accounting systems (3).

Currently NBTS operates a network of regional centres and satellite centres all coordinated at the head office in Nairobi. At the head office are the National Director, and line managers as shown in Figure 1. At the regional centres are medical directors assisted by technical services managers, (also referred to as Technical Directors), as their deputies to implement policies and coordinate activities at the regional level.
Satellite centres serve as storage and distribution points within the regions and are manned by staff from the respective hospitals. Hospital transfusion units are managed by the respective hospitals as part of the hospital laboratories. Both satellite and hospital transfusion units are supervised by technical director and quality assurance officers from their respective regional blood transfusion centres (1).

\section{CORE FUNCTIONS OF THE REGIONAL BLOOD TRANSFUSION SERVICES}

Blood donor services department: This department has two major units namely recruitment unit and donor clinics units. Recruitment unit carries out donor education, mobilisation, recruitment and retention of donors. It also handles public relations and marketing of the centres activities. Donor clinics handles, selection of donors, counselling both pre and post donation, blood collection, donor care and referrals of donors who need medical services.

Technical services department: This department handles, blood testing, sorting, preparation of blood components, storage and issue/distribution of safe units to hospitals. Note unsafe units are quarantined and incinerated.

Administrative support department: This department ensures policies are implemented, logistics support is given and information flow as well as networking through information technology unit is done. Appropriate use of blood and blood products at hospital level has been addressed through formation of hospital transfusion committees and development of appropriate use of blood and blood products guidelines as well as development of haemovigilance manual for hospital use.

\section{ACHIEVEMENTS OF THE BLOOD TRANSFUSION SERVICE}

(i) Over the years blood donations from voluntary non-remunerated donors has increased from merely 6,000 units per year in 2002 to 130,000 units in 2007. The country's blood needs currently is estimated to stand at 200,000units.

(ii) Blood transfusion service has evolved from a unit within the hospital laboratory services to a well coordinated NBTS with a network of RBTCs and satellites centres with dedicated staff, transport and funding and hence able to meet $80 \%$ of all blood needs of major hospitals in the country.

(iii) Blood donation has shifted from family/ replacement donors as a major source of blood to voluntary non remunerated donors. Blood 
is screened $100 \%$ for transfusion transmissible infections (TTIs) as per the policy (i.e for HIV, hepatitis B, hepatitis C and syphilis).

(iv) NBTS is able to prepare blood components and paediatric packs, and $20-40 \%$ of blood collected is separated into components.

(v) There has been expansion in the staff establishment including other cadres with varied expertise. These include nurses, marketers, information systems and computer technology experts, accountants and blood transfusion medical specialists, unlike in the past where only laboratory technologists were running the blood transfusion units.

(vi) There has also been increase in the numbers of staff in general to almost five times what it was in the year 2002.

(vii) Collaborations with more partners on donor mobilization and planned recruitment as is the case with Blood link Foundation and Hope World wide, to expand the blood donor base. Collaboration with partner African Society for Blood Transfusion (AFSBT) Kenya chapter, has assisted in setting up hospital transfusion committees to ensure safe blood use at hospital level (8-11).

All these achievements have been made possible by assistance from USG PEPFAR funds through CDC and also by contribution from Japan Government through JICA (6-13).

Tasks to be undertake in the near future:

(i) To centralise blood donor testing using automated machines which should further improve blood safety. (ii) Start fixed donation sites at strategic towns to further improve reach outs for donors out of school.

(iii) Continue working on legislation of the blood policy and push for semi autonomy.

(iv) Put up additional satellite centres to further improve on blood distribution to hospitals.

\section{REFERENCES}

1. Policy guidelines for blood transfusion in Kenya. $1^{\text {st }}$ edition.

2. World Health Assembly resolution WHA 28.72 of 1972 and of 1989.

3. Websites: Ministry of Health Government of Kenya http:/www.state house Kenya. go.ke./ governmentlhealth. htm.

4. Kenya Red Cross http://www.kenya red cross.org/

5. Kenya Medical Research Institute - KEMRI http:// www.kemri.org/

6. Family Health International- FHI http://www.fhi.org/ en/country protiles/kenya/index.htm.

7. United States Agency for International Development - USAID http://www usaid.gov/ke/index.html

8. Japanese International Cooperation Agency JICA http:www.jica.go.jp/Kenya/English/

9. American Association of Blood Banks - AABB http:www.aabb.org/content.

10. Centre for Disease Control and Prevention - CDC http://www.aabb.org/content

11. African Society for Blood Transfusion http://www. afsbt.org/

12. National Standards for Blood Transfusion Services in Kenya, MOH GOK 1st edition, 2007.

13. Haemovigilance manual for hospital transfusion services in Kenya. 1st edition, 2009. 